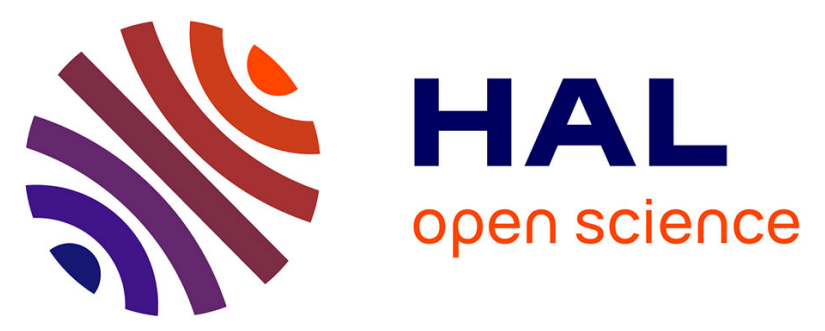

\title{
Physical origin of the third order nonlinear optical response of orthogonal pyrrolo-tetrathiafulvalene derivatives
}

Konstantinos Iliopoulos, Robert Czaplicki, Hasnaa El Ouazzani, Jean-Yves Balandier, Marcos Chas, Sébastien Goeb, Marc Sallé, Denis Gindre, Bouchta Sahraoui

\section{To cite this version:}

Konstantinos Iliopoulos, Robert Czaplicki, Hasnaa El Ouazzani, Jean-Yves Balandier, Marcos Chas, et al.. Physical origin of the third order nonlinear optical response of orthogonal pyrrolotetrathiafulvalene derivatives. Applied Physics Letters, 2010, 97 (10), pp.101104 - 101104-3. 10.1063/1.3482943 . hal-01389330

\section{HAL Id: hal-01389330 https://hal.science/hal-01389330}

Submitted on 8 Oct 2021

HAL is a multi-disciplinary open access archive for the deposit and dissemination of scientific research documents, whether they are published or not. The documents may come from teaching and research institutions in France or abroad, or from public or private research centers.
L'archive ouverte pluridisciplinaire HAL, est destinée au dépôt et à la diffusion de documents scientifiques de niveau recherche, publiés ou non, émanant des établissements d'enseignement et de recherche français ou étrangers, des laboratoires publics ou privés. 


\section{Physical origin of the third order nonlinear optical response of orthogonal pyrrolo- tetrathiafulvalene derivatives}

Cite as: Appl. Phys. Lett. 97, 101104 (2010); https://doi.org/10.1063/1.3482943

Submitted: 06 July 2010 . Accepted: 25 July 2010 . Published Online: 07 September 2010

K. Iliopoulos, R. Czaplicki, H. El Ouazzani, et al.

\section{ARTICLES YOU MAY BE INTERESTED IN}

Effect of the counter cation on the third order nonlinearity in anionic Au dithiolene complexes

Applied Physics Letters 101, 261105 (2012); https://doi.org/10.1063/1.4772476

Femtosecond carrier dynamics and saturable absorption in graphene suspensions Applied Physics Letters 95, 191911 (2009); https://doi.org/10.1063/1.3264964

Influence of solvent contribution on nonlinearities of near infra-red absorbing croconate and squaraine dyes with ultrafast laser excitation

Journal of Applied Physics 114, 133103 (2013); https://doi.org/10.1063/1.4823817

Challenge us.

What are your needs for periodic signal detection?

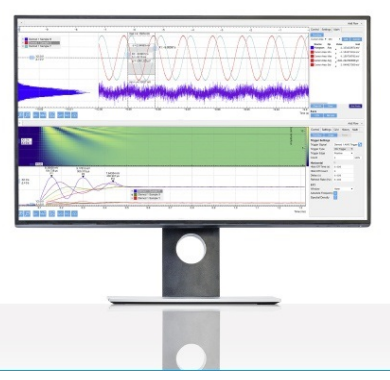

Zurich

Instruments 


\title{
Physical origin of the third order nonlinear optical response of orthogonal pyrrolo-tetrathiafulvalene derivatives
}

\author{
K. Iliopoulos, R. Czaplicki, H. El Ouazzani, J. Y. Balandier, M. Chas, S. Goeb, M. Sallé, \\ D. Gindre, and B. Sahraoui ${ }^{\text {a) }}$ \\ Institut des Sciences et Technologies Moléculaires d'Angers (Moltech Anjou), CNRS UMR 6200, \\ Université d'Angers, 2 Bd Lavoisier, 49045 Angers Cedex, France
}

(Received 6 July 2010; accepted 25 July 2010; published online 7 September 2010)

\begin{abstract}
We present the third order nonlinear optical study of tetrathiafulvalene-based molecular corners. Degenerate four-wave mixing measurements have been done to provide information about the magnitude and the origin of the nonlinearity, while the nonlinear absorption has been separately measured by performing "open aperture" Z-scan measurements. The response has been found to be strongly dependent upon the structure of the molecular corners. (c) 2010 American Institute of Physics. [doi:10.1063/1.3482943]
\end{abstract}

During the past few years the nonlinear optical (NLO) response of organic materials was studied in order to find suitable systems for optoelectronic/photonic applications. In this direction tetrathiafulvalene (TTF)-based molecules have been widely investigated. ${ }^{1-5}$ Due to their extended $\pi$ system and the strong electron donating character of the TTF-moiety (leading to charge transfer within the molecule), such systems exhibit very interesting NLO properties. In this work we report on the third order nonlinear optical response of orthogonal tetrathiafulvalene-based bricks (Fig. 1), which can be self-organized into orthogonal dimers through metal assisted assembly with $\mathrm{Pd}(\mathrm{II})$ or Pt(II) salts. The details of the synthetic procedure have been reported recently in Ref. 6.

The third order nonlinear optical response of the samples has been investigated by the well known degenerate fourwave mixing (DFWM) method. ${ }^{7}$ For the needs of the measurements the frequency doubled exit $(532 \mathrm{~nm})$ of a modelocked Nd:YAG laser, providing 30 ps duration laser pulses with $1 \mathrm{~Hz}$ repetition rate has been utilized, while the details of the experimental setup are given elsewhere. ${ }^{8}$ With this experimental setup and by changing the polarization of the pump and probe waves, the different elements of the third order susceptibility $\chi^{(3)}$ were determined, by reference to the $\mathrm{CS}_{2}$ solvent. For the third order nonlinear optical investigation several solutions for each of the systems, exhibiting different concentrations in $\mathrm{CH}_{2} \mathrm{Cl}_{2}$ have been prepared and put into $1 \mathrm{~mm}$ thick quartz cells. In Fig. 2 the intensity of the DFWM signal $I_{4}$ as a function of the intensity of the pump beam $\mathrm{I}_{1}$ is shown, for different concentrations of the sample $\mathrm{S} 1$ as well as of the neat solvent $\mathrm{CH}_{2} \mathrm{Cl}_{2}$. It is obvious that there is good dependence of the DFWM signal upon the pump intensity as theoretically expected. ${ }^{9}$ Similar procedure has been followed for the other two systems S2 and S3. From these measurements the optimal concentration $\mathrm{C}_{\text {opt }}$ has been determined as the concentration which results to the maximum $\mathrm{I}_{4}$ signal. The $\mathrm{C}_{\mathrm{opt}}$ has been found to be 2.5 $\times 10^{-4} \mathrm{~mol} / \mathrm{L}, 5.0 \times 10^{-4} \mathrm{~mol} / \mathrm{L}$, and $5.0 \times 10^{-4} \mathrm{~mol} / \mathrm{L}$ for the systems S1, S2, and S3, respectively. In Table I the $\chi^{(3)}$ values corresponding to the optimal concentrations, as well as the determined second order hyperpolarizability $(\gamma)$ val- ues of the molecules can be seen. In the same table the value of $\mathrm{CS}_{2}$ is shown for comparison reasons. By comparing the results between the different TTF-based corners, it can be seen that $\mathrm{S} 2$ exhibits higher nonlinearity than $\mathrm{S}_{1}$ by about a factor of 2. This result could be expected because changing the $\mathrm{Pt}(\mathrm{II})$ by a $\mathrm{Pd}(\mathrm{II})$ corner complex can change the charge transfer efficiency in the molecule. Moreover by comparing with the molecule $\mathrm{S} 3$ the effective $\gamma$ values are enhanced by a factor of about 5 and 2.5 compared with that of the molecules S1 and S2, respectively, an effect which in this case, is assignable to the introduction of two triethyphosphine ligands in a cis position on the metal (S3), instead of a 1,3bis(diphenylphosphino)propane ligand (S1 and S2). Moreover the second order hyperpolarizability of the TTF compounds (S1-S3) is higher compared with that of neat $\mathrm{CS}_{2}$, by about four orders of magnitude, showing that the investigated compounds exhibit significant nonlinear optical response.

In the picosecond regime and for isotropic materials the electronic and nuclear contributions to the nonlinearity are<smiles>CS(=O)(=O)C1=C(S)SC(=C2Sc3cn(-c4ccncc4)cc3S2)S1</smiles>

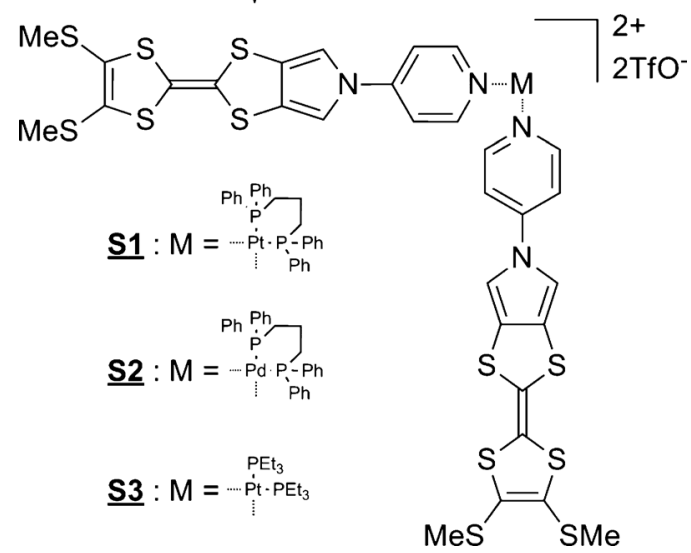

FIG. 1. Chemical structures of the investigated systems.

${ }^{a)}$ Electronic mail: bouchta.sahraoui@univ-angers.fr. 


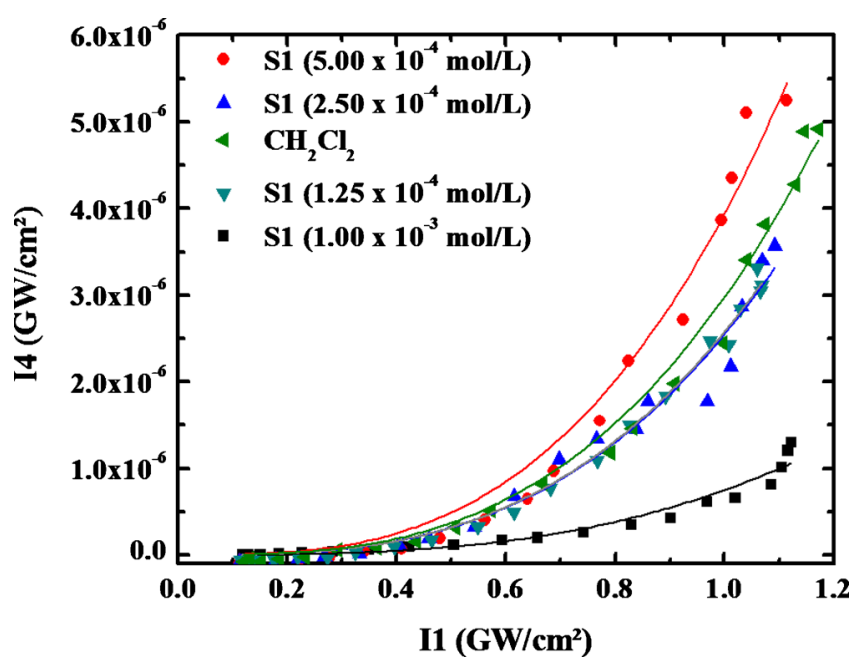

FIG. 2. (Color online) Reflectivity of the DFWM as a function of the pump intensity for several concentrations of the S1 sample and the neat solvent.

dominant. In order to find out the physical origin of the nonlinearity further DFWM measurements have been carried out by changing the polarizations of the pump and the probe beams. In this way the relations between the elements of the third order susceptibility tensor were derived and are given below, in the following Eqs. (1) and (2), for the molecules S1 and S2, respectively:

$$
\begin{aligned}
& \chi_{x x x x}^{(3)} \approx 1.6 \chi_{x x y y}^{(3) \exp } \approx 2.0 \chi_{y x y x}^{(3) \exp } \approx 1.8 \chi_{y x x y}^{(3) \exp }, \\
& \chi_{x x x x}^{(3)} \approx 1.8 \chi_{x x y y}^{(3) \exp } \approx 2.1 \chi_{y x y x}^{(3) \exp } \approx 2.0 \chi_{y x x y}^{(3) \exp } .
\end{aligned}
$$

By comparing these results with the theoretically predicted for nuclear and electronic contributions ${ }^{10}$ it becomes clear that the electronic contribution to the nonlinearity is stronger. To provide quantitative results of the two contributions, the ratios $\chi_{x x x x}^{(3) e l} / \chi_{x x x x}^{(3)}$ and $\chi_{x x x x}^{(3) n u} / \chi_{x x x x}^{(3)}$ were determined and have been found to be around 1.10 and 0.10 , respectively, for all three systems. This result could be expected as the TTF is a well known electron donor and as a result strong charge transfer takes place along these molecules, leading to strong electronic contribution on the response.

In order to separately determine the nonlinear absorption of the molecules S1-S3, "open aperture" Z-scan measurements have been carried out, following the procedure described elsewhere. ${ }^{11,12}$ For these measurements the same laser system has been employed. Briefly, the transmittance after the sample is measured, while moving it along the transmission axis of the laser beam. By fitting the experimental data according to equations which can be found in the literature ${ }^{11,12}$ the nonlinear absorption parameter $(\beta)$, the $\operatorname{Im} \chi^{(3)}$ and $\operatorname{Im} \gamma$ values are obtained.

TABLE I. Nonlinear optical parameters determined from the DFWM measurements (30 ps, $532 \mathrm{~nm})$.

\begin{tabular}{lcc}
\hline $\begin{array}{c}\text { Sample } \\
\text { (optimal concentration) }\end{array}$ & $\begin{array}{c}\chi^{(3)} \times 10^{-21} \\
\left(\mathrm{~m}^{2} / \mathrm{V}^{2}\right)\end{array}$ & $\begin{array}{c}\gamma \times 10^{-45} \\
\left(\mathrm{~m}^{5} / \mathrm{V}^{2}\right)\end{array}$ \\
\hline $\mathrm{S} 1\left(2.50 \times 10^{-4} \mathrm{~mol} / \mathrm{L}\right)$ & 1.13 & 1.32 \\
$\mathrm{~S} 2\left(5.00 \times 10^{-4} \mathrm{~mol} / \mathrm{L}\right)$ & 1.11 & 2.71 \\
$\mathrm{~S} 3\left(5.00 \times 10^{-4} \mathrm{~mol} / \mathrm{L}\right)$ & 2.29 & 6.44 \\
$\mathrm{CS}_{2}$ & 19.4 & $4.71 \times 10^{-4}$ \\
\hline \hline
\end{tabular}

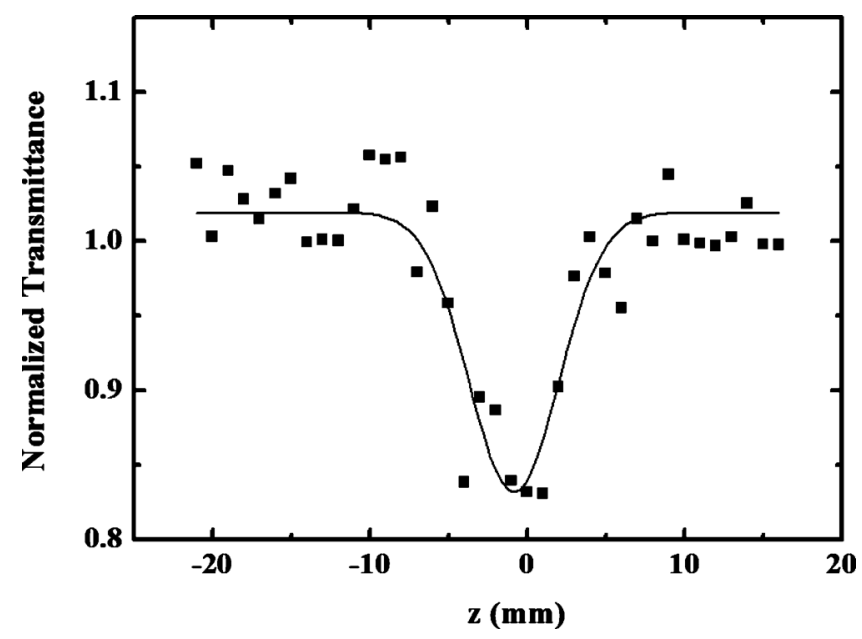

FIG. 3. "Open-aperture Z-scan" obtained for the $\mathrm{S} 1$ system $(1.0 \mathrm{mM}$ in $\mathrm{CH}_{2} \mathrm{Cl}_{2}$ ) at $\mathrm{E}=5.1 \mu \mathrm{J}$.

Prior to the measurements calibration of the nonlinear absorption setup has been done by investigating samples of $\mathrm{C}_{60}$ fullerene, which is a well known optical limiter. The imaginary part of the second order hyperpolarizability $(\operatorname{Im} \gamma)$ has been measured to be $0.21 \times 10^{-45} \mathrm{~m}^{5} / \mathrm{V}^{2}$, corresponding to $0.15 \times 10^{-31}$ esu, which is in very good agreement with already reported values. ${ }^{12,13}$ Then "open aperture" Z-scan measurements have been done for several concentrations of each of the TTF compounds and for various incident laser intensities. The corresponding solvent $\left(\mathrm{CH}_{2} \mathrm{Cl}_{2}\right)$ has been separately measured in all cases and the contribution to the nonlinear absorption, under the same experimental conditions, has been found to be negligible, so the nonlinear absorption of the solutions can be totally attributed to the dissolved TTF-corners. Transmittance minima have been found around the focal plane indicating reverse saturable absorption (RSA) character of the samples. In Fig. 3 a characteristic "open aperture" Z-scan of the system S1 exhibiting $1 \mathrm{mM}$ concentration in $\mathrm{CH}_{2} \mathrm{Cl}_{2}$ can be seen, obtained at $\mathrm{E}$ $=5.1 \mu \mathrm{J}$, while in Fig. 4 the $\operatorname{Im} \chi^{(3)}$ values for all investigated systems are shown as a function of concentration. Very good concentration dependence is obtained for all the systems, verifying that no aggregation or saturation of the nonlinear optical response was present during the measurements.

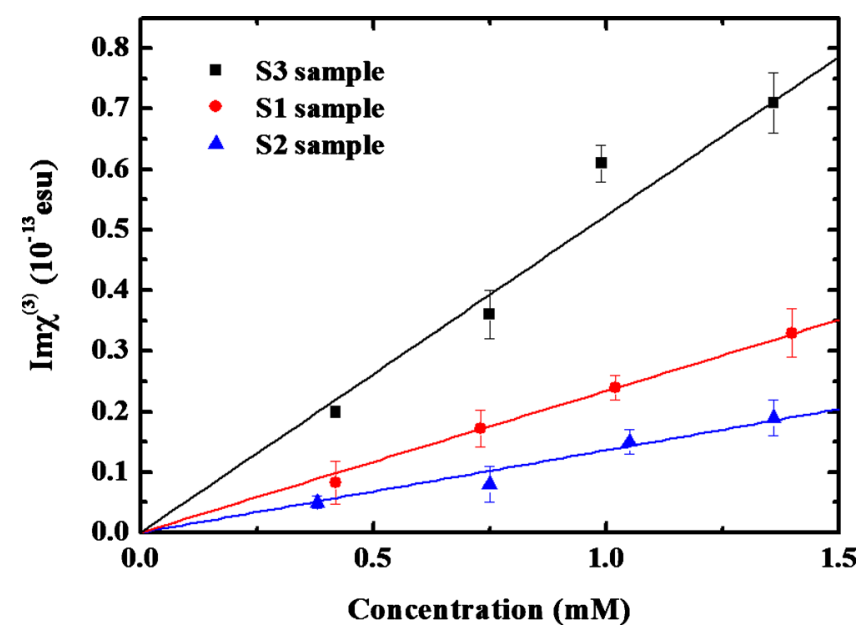

FIG. 4. (Color online) Concentration dependence of the nonlinear absorption for the S1-S3 molecules. 
TABLE II. Nonlinear optical parameters determined from the nonlinear absorption measurements (30 ps, $532 \mathrm{~nm})$.

\begin{tabular}{lccccc}
\hline \hline Sample & $\begin{array}{c}\beta^{\mathrm{a}} \\
\left(10^{-11} \mathrm{~m} / \mathrm{W}\right)\end{array}$ & $\begin{array}{c}\operatorname{Im} \chi^{(3) \mathrm{a}} \\
\left(10^{-13} \mathrm{esu}\right)\end{array}$ & $\begin{array}{c}\operatorname{Im} \chi^{(3) \text { a }} \\
\left(10^{-21} \mathrm{~m}^{2} / \mathrm{V}^{2}\right)\end{array}$ & $\begin{array}{c}\operatorname{Im} \gamma \times 10^{-31} \\
(\mathrm{esu})\end{array}$ \\
\hline S1 & 0.55 & 0.33 & 0.46 & 0.12 & 0.17 \\
S2 & 0.32 & 0.19 & 0.27 & 0.07 & 0.10 \\
S3 & 1.19 & 0.71 & 0.99 & 0.26 & 0.37 \\
\hline \hline
\end{tabular}

${ }^{a}$ Corresponding to concentration $1 \mathrm{mM}$ of the samples in $\mathrm{CH}_{2} \mathrm{Cl}_{2}$.

In Table II the determined $\beta$ and $\operatorname{Im} \chi^{(3)}$ values corresponding to $1 \mathrm{mM}$ concentration samples can be seen, as well as the imaginary part of the second order hyperpolarizability $(\operatorname{Im} \gamma)$ which was determined from the concentration dependent investigation. It is obvious that the S3 system exhibits higher RSA than the other two systems, following the same trend with the second order hyperpolarizability values of the systems (Table I). On the contrary, the S2 system exhibits lower nonlinear absorption than S1. Additional measurements which were carried out for the B1 ligand revealed that it has negligible nonlinear absorption, compared with the other two systems, under the same experimental conditions.

By comparing the results of Tables I and II it is derived that the contribution of nonlinear refraction to the total response is dominant. In particular the $\operatorname{Im} \gamma$ values are at least one order of magnitude lower than the $\gamma$ values, while the $\operatorname{Im} \gamma / \gamma$ ratios are $0.13,0.04$, and 0.06 for the $\mathrm{S} 1, \mathrm{~S} 2$, and $\mathrm{S} 3$ molecules respectively.

In this work the physical origin of the third order NLO response, as well as the corresponding NLO parameters have been determined by a combination of DFWM and "open aperture" Z-scan measurements, while strong dependence upon the structure of the systems has been found. The high NLO response of the corners combined with the possibility to further tune it by changing the molecular structure makes these systems very promising candidates for a variety of optoelectronic/photonic applications.
The authors acknowledge financial support from the ANR PNANO-TTF-Based Nanomat (Grant No. ANR-07NANO-030-02) project.

${ }^{1}$ B. Sahraoui, X. Nguyen Phu, T. Nozdryn, and J. Cousseau, Synth. Met. 115, 261 (2000).

${ }^{2}$ I. Fuks-Janczarek, J. Luc, B. Sahraoui, F. Dumur, P. Hudhomme, J. Berdowski, and I. V. Kityk, J. Phys. Chem. B 109, 10179 (2005).

${ }^{3}$ B. Sahraoui, X. Nguyen Phu, M. Salle, and A. Gorgues, Opt. Lett. 23, 1811 (1998)

${ }^{4}$ B. Sahraoui, G. Rivoire, N. Terkia-Derdra, M. Salle, and J. Zaremba, J. Opt. Soc. Am. B 15, 923 (1998).

${ }^{5}$ N. Terkia-Derdra, R. Andreu, M. Salle, E. Levillain, J. Orduna, J. Garin, E. Orti, R. Viruela, R. Pou-Amerigo, B. Sahraoui, A. Gorgues, J.-F. Favard, and A. Riou, Chem.-Eur. J. 6, 1199 (2000).

${ }^{6}$ J.-Y. Balandier, M. Chas, P. I. Dron, S. Goeb, D. Canevet, A. Belyasmine, M. Allain, and M. Salle, J. Org. Chem. 75, 1589 (2010).

${ }^{7}$ R. L. Abrams and R. C. Lind, Opt. Lett. 2, 94 (1978).

${ }^{8}$ I. Fuks-Janczarek, B. Sahraoui, I. V. Kityk, and J. Berdowski, Opt. Commun. 236, 159 (2004).

${ }^{9}$ J. L. Brédas, C. Adant, P. Tackx, A. Persoons, and B. M. Pierce, Chem. Rev. 94, 243 (1994).

${ }^{10}$ J. P. Bourdin, X. Nguyen Phu, G. Rivoire, and J. M. Nunzi, Mol. Cryst. Liq. Cryst. B: Nonlinear Opt. 7, 1 (1994).

${ }^{11}$ M. Sheik-Bahae, A. A. Said, T. H. Wei, D. J. Hagan, and E. W. Van Stryland, IEEE J. Quantum Electron. 26, 760 (1990).

${ }^{12}$ R. Zaleśny, O. Loboda, K. Iliopoulos, G. Chatzikyriakos, S. Couris, G. Rotas, N. Tagmatarchis, A. Avramopoulos, and M. G. Papadopoulos, Phys. Chem. Chem. Phys. 12, 373 (2010).

${ }^{13}$ S. Couris, E. Koudoumas, F. Dong, and S. Leach, J. Phys. B 29, 5033 (1996). 